\title{
CONSUMERS' WILLINGNESS TO PAY (WTP) OF SPECIAL TAX FOR NON-GREEN VEHICLES TOWARDS ENVIRONMENTAL PERFORMANCE IN MALAYSIA
}

\author{
Sharul Shahida Shakrein Safian ${ }^{1}$ \\ Faculty of Economics \& Management, \\ Universiti Putra Malaysia \\ (Email: sharulshahida88@gmail.com) \\ Hanny Zurina Hamzah ${ }^{2}$ \\ Faculty of Economics \& Management, \\ Universiti Putra Malaysia, \\ (Email: hanny@upm.edu.my)
}

Accepted date: 25-06-2019

Published date: 15-07-2019

To cite this document: Safian, S. S. S., \& Hamzah, H. Z. (2019). Consumers' Willingness to Pay (WTP) of Special Tax for Non-Green Vehicles towards Environmental Performance in Malaysia. Journal of Tourism, Hospitality and Environment Management, 4(15), 66-77.

DOI: $10.35631 /$ JTHEM.415007

\begin{abstract}
The use of the green concept in the automotive industry as an energy-efficient transport innovation is still regarded as a new technology in Malaysia. It also has the potential to alleviate environmental issues in order to improve environmental performance in the automotive industry context. As such, the significance of green technology has become a growing concern, especially among developing countries. The purpose of this study is to determine consumers' willingness to pay for green vehicles towards solving environmental issues in Malaysia. In order to achieve this, the consumers' willingness to pay (WTP) and their preferences were examined using the contingent valuation method (CVM) as found in previous studies. Data was gathered using survey questionnaires which were distributed among 445 Malaysians so as to know their preferences in terms of green vehicles and green practices. The data was analysed using Economic Valuation Method. The result shows that Malaysians are willing to pay the price increase in road tax by $6.49 \%$ maximum level for non-green vehicles as well as all control variables included in the doubled-bounded case. On the other hand, for a single-bounded case, the maximum value is $7.91 \%$ which is higher as respondents were given single WTP amount for acceptance compared to the double-bounded case when the initial WTP was followed by another different amount.
\end{abstract}

Keywords: Willingness To Pay (WTP), Contingent Valuation Method (CVM), Green Vehicles, Environmental Issues

\section{Introduction}

Environmental issues are often associated with toxic wastes, pollution and many other issues which are debated globally and cut across the different walks of life. However, in most of the 
cases, people are often unaware that vehicles also have a role in contaminating and harming our common habitat (Kazdin, 2009). The production of environmentally friendly green vehicles proffers solution to this problem because it produces lesser emissions (Chapman, 2007). Generally, people are reluctant to reduce the time they spend driving since it is believed that vehicles are necessary in our daily life.

Green vehicles ensure the quality of the environment as there is a decrease in their emission of carbon dioxide (Beliveau, 2010). It is imperative to note that green vehicles do not just bolster environmental protection, but they also lessen fuel consumption and give better mileage. For instance, in term of fuel consumption, the distance covered by green vehicles is around $30 \mathrm{~km} /$ litre compared to non-green vehicles which cover only $20 \mathrm{~km} / \mathrm{litre}$. In order to address the global warming problem, green technologies must be promoted for a cleaner environment. For example, solar based energy, non-petrol-expending (e.g. Bikes) and green vehicles have helped in making the environment more conducive for everybody to live in. Green vehicles have been viewed as environmentally friendly because of their fuel-saving specification (Heffner, 2007). Carbon emission $\left(\mathrm{CO}_{2}\right)$ has increased rapidly over the past few decades. Almost 30 billion tonnes of $\mathrm{CO}_{2}$ are emitted to the atmosphere as a result of human activities each year (Goodall, 2007).

Malaysia ranked behind South Korea, China, Taiwan, Thailand and Indonesia in the automotive industry. (WEF, 2015). In term of emissions from industries, one of the main contributors to this issue is the automotive industry activities, as a result of the production of vehicles. Proton was established as Malaysia's national car in 1983 (Jomo, 1994). The company supported the advancement green technology and updating of innovative and designing capacities which additionally upgraded Malaysia as the base for worldwide automotive manufacturers. It delivered up to 614,664 vehicles including 563,883 passenger vehicles and 50,781 commercial vehicles in 2015. The increase in percentage of sales of cars registered a peripheral growth of $3.05 \%$ yearly. Unfortunately, unlike 5years ago, the automobile industry only indicated a yearly growth of $2 \%$ as presented below.

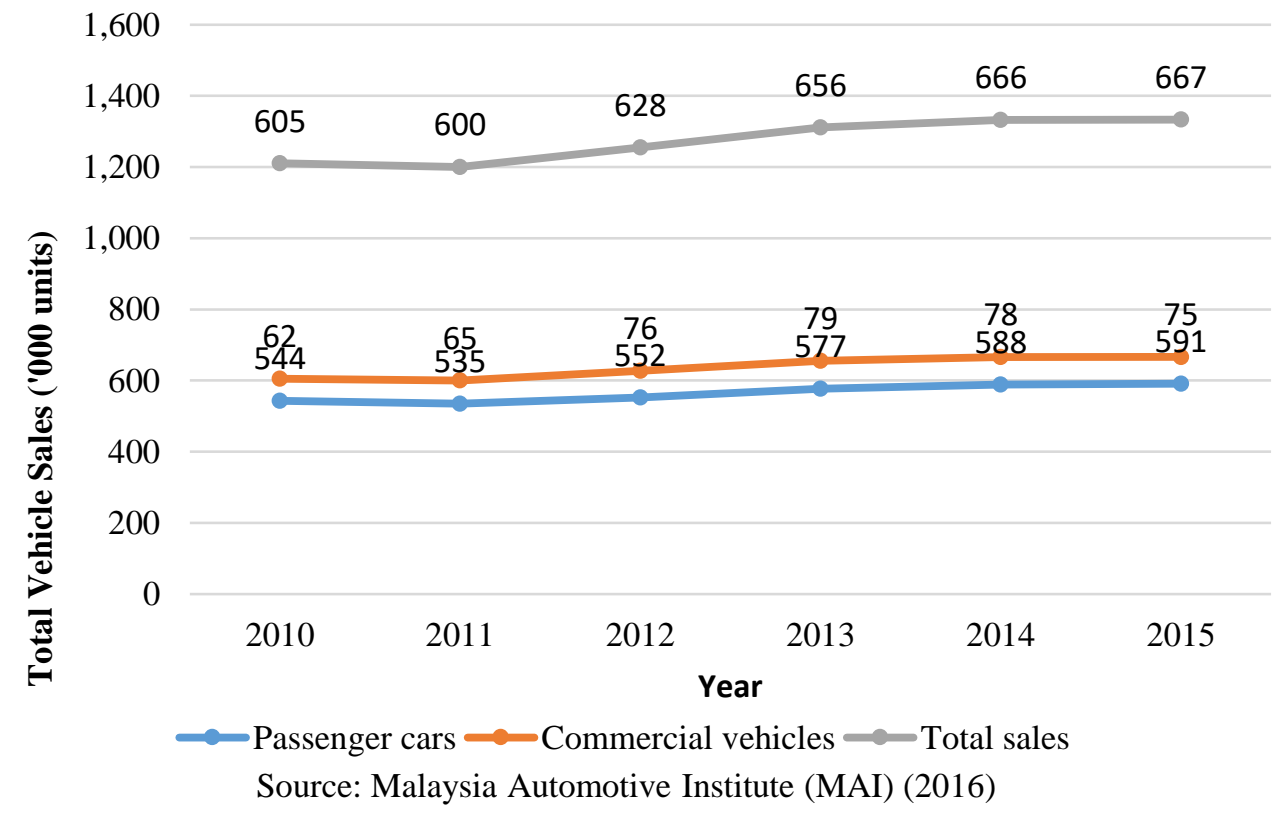

Figure 1.1: Total Vehicle Sales in Malaysia between 2010 and 2015 
According to Figure 1.1, it is observed that the total vehicle sales (including passenger and commercial vehicles) increased between 2010 and 2015. This situation also suggests an increasing vehicle buying trend among Malaysians, which witnessed an increasing number of private vehicle ownerships. This development in private vehicle ownership certainly will worsen the level of $\mathrm{CO}_{2}$ emissions due to the increasing number of vehicles on the road apart from traffic congestions (Barth \& Bariboonsomsin, 2008). $\mathrm{CO}_{2}$ emissions can be lowered by improving traffic operations, specifically through the reduction of traffic congestion. In addition, by encouraging the population to use environmentally friendly vehicles and the use of carbon-neutral alternative fuels, the $\mathrm{CO}_{2}$ emissions could be significantly reduced in the future. Malaysia is committed to reduce $40 \%$ of carbon intensity by 2010 (Chua \& Oh, 2010). In order to achieve this goal, the nation must work to increase fuel efficiency, preserve the environment, and conserve environmental resources. The transformation and the initiative to green is imperative in all aspects, from consumer and also supply chain of the domestic automotive industry in order to overcome the problem of carbon emissions from vehicles. Other than that, the tax system on vehicles or road tax may also be granted one of the indirect medium to overcome this issue. This is because every vehicle is required to pay a road tax according to the engine capacity (cc), so a special tax should be set up for non-green vehicles based on the rate itself. The reason for implementing this special tax for non-green vehicles only rather than all vehicles is because the level of emissions from non-green vehicles are higher compared to green vehicles. Furthermore, the payment method would be one of the indirect ways to compensate the populace for substituting their current vehicles with green vehicles in order to reduce the emissions from the vehicles. Table 1.1 is the price list of road tax in Malaysia based on the type of vehicles and engine capacity (cc); this gives more insight as to why green vehicles are needed.

Table 1.1: Price List of Road Tax in Malaysia

\begin{tabular}{|c|c|c|c|}
\hline \multicolumn{4}{|c|}{ For private registration in Peninsular Malaysia } \\
\hline $\begin{array}{c}\text { Engine } \\
\text { Capacity (cc) }\end{array}$ & Base Rate & $\begin{array}{c}\text { Progressive rate } \\
\text { (per cc) }\end{array}$ & Total road tax \\
\hline 1000 and below & RM20.00 & - & RM20.00 \\
\hline 1001 to 1200 & RM55.00 & - & RM55.00 \\
\hline 1201 to 1400 & RM70.00 & - & RM70.00 \\
\hline 1401 to 1600 & RM90.00 & - & RM90.00 \\
\hline 1601 to 1800 & RM200.00 & RM0.40 & RM200.40 to RM280.00 \\
\hline 1801 to 2000 & RM280.00 & RM0.50 & RM280.50 to RM380.00 \\
\hline 2001 to 2500 & RM380.00 & RM1.00 & RM381.00 to RM880.00 \\
\hline 2501 to 3000 & RM880.00 & RM2.50 & RM882.50 to RM2130.00 \\
\hline 3001 and above & RM2130.00 & RM4.50 & RM2134.50 an above \\
\hline
\end{tabular}

Source: Road Transport Department Malaysia (2016)

Based on the price list, the total amount of road tax depends on the types and cc of the vehicles and this applies to other countries as well. It means that the higher the cc of the vehicles, the higher the amount of road tax as higher cc of vehicles will contribute a higher level of emissions towards the environment in the case of non-green vehicles. The special tax or environmental tax is the tax paid on environmental pollutants or on goods whose use produce such pollutants. It has many important advantages, such as environmental effectiveness, economic efficiency, the ability to raise public revenue, and transparency. At the same time, environmental taxes have been successfully used to address environmental issues such as air pollution in this case. 
Taxes on pollution provide clear incentives to polluters to reduce emissions and seek out cleaner and sustainable alternatives.

The number of private vehicles increases along with an improved standard of living, as shown in Figure 1.1. As Malaysians perceive vehicles as necessity, the perception will relatively increase the number of private vehicles on the road. It implies that Malaysians are still not conscious about the adverse impact of emissions produced by the private vehicles, particularly by the conventional vehicles (Kasipillai \& Chan, 2008). It contributes to the damage done to the environment. Thus, reducing the number of private vehicles seems very difficult as it is considered an important need in daily life. Most Malaysian people does not aware of green vehicles in reducing emissions towards environmental performance. Reasoning from these matters, initiative that can be rolled out to reduce environmental pollution is via mandatory payment method of road tax for non-green vehicles. This study therefore provides insights in relation to consumers' level of acceptance and preferences for green vehicles.

\section{Literature Review}

There are many elements affecting the intention to buy green vehicles. Jason, Oliver and Lee (2010) examined purchase expectations of green vehicles in a cross-cultural investigation. They found that the preference to look for information and self-image regarding green products have a positive association with the intention to buy green vehicles among purchasers from the United States of America (USA) and South Korea. A study was carried out by Ramjerdi and Rand (1999), they analysed the improvement of models of the decision and interest for clean fuel and clean vehicles in Norway. They observed that individuals favoured clean fuel vehicles in their second vehicle purchase. Hensher (1982) examined the demand elasticity for electrical vehicles (EVs) in terms of operating cost, price tag, and the scope of the EVs. He found that higher future fuel costs could be a critical figure towards EV demand. Brownstone et al., (2000) observed that respondents favoured compacted natural gas and methanol to gasoline, according to the data generated from households in California. However, only educated respondents favoured EVs by inspecting and uncovering preferences for option of fuel vehicles.

Kishi and Satoh (2005) investigated the intention of individuals towards the purchase of a lowcontamination vehicle in Tokyo and Sapporo. They found that citizens of Sapporo demonstrated a strong concern towards the environment. However, concerns about the environment do not really urge them to buy low-contamination vehicles. Potoglou and Kanaroglou (2007) examined the elements and motivations for Canadians' adoption of cleaner vehicles. The study demonstrated that a reduction in the money related costs, purchase, tax reliefs and low outflow rates may urge households to embrace cleaner vehicles. Then, motivating forces was not found to have a huge impact on the adoption of these sorts of vehicles. For example, free parking and authorization to drive on high inhabitancy vehicle paths.

Heutel \& Muehlegger (2008) found that just 11 percent of United States citizens are extremely willing to pay a premium for these sorts of vehicles. Despite the findings, numerous consumers in the United States desire to buy environmentally well-disposed vehicles. At the same time, it was discovered that buyers who indicated a strong willingness to pay for these vehicles were mostly females and highly educated (Creusen, 2010). A similar study by Creusen (2010), found that the proprietors of the green vehicles could be recognized as individuals with a much more elevated level of education and household pay. On top of that, they were roughly four years more established than the normal new vehicle purchase. 
In term of early adopters who pay more in order to accomplish a quality environment, they are most probably motivated to purchase green vehicles as a result of their expectations of money related reward. For instance, they purchase the green vehicles with the hope that the fuel reserve funds will surpass the additional upfront cost. Approaches like tax incentives influence consumers' choices to purchase green vehicles (Heutel \& Muehlegger, 2008). Moreover, their discoveries relate to technology policy. It is specifically a policy which is proposed to empower low-carbon technologies. As a conclusion, this study addresses the maximum percentage increase that Malaysian people willing to pay regarding pollution from vehicles by using mandatory payment method or taxes on environment. Most past studies investigate willingness to pay in term of demographic factors and characteristics of green vehicles. However, studies regarding willingness to pay of maximum amount or percentage increase on road tax price for non-green vehicles (which is the main contributor towards air pollution from transportation) are rarely found.

\section{Methodology}

In this study, the investigation towards green vehicles was conducted by running a scenario. The scenario was designed to investigate consumers' willingness to pay for an increased amount in road tax for conventional vehicles. The income from the increased amount of road tax on conventional vehicles will help the government to fund several zero emissions programs related to transportation sector in Malaysia. Consumers who have a higher level of green awareness should opt for a high percentage of road tax on conventional vehicles. Besides, in order to preserve the environment to become cleaner the demand for green vehicles hope to be increased. This scenario indirectly influences the consumers' awareness towards green vehicle in order to protect the environment. Socio-demographic variables (e.g. Gender, income, age, status, education, employment and race) were used in order to categorize the consumer preferences.

Data was collected using survey questionnaires which were personally distributed to respondents. A total of 445 questionnaires were distributed among Malaysian people age 18 years old and above. All were returned to the researcher. However, only 427 were found useful for the analysis as the remaining 18 questionnaires were incomplete. The analysis was done using STATA software. The data collected was analysed using the Economic Valuation Method.

In this study, the WTP function also includes bid price since respondents' answers are expected to be affected by the bid price offered. The model specification is expressed as follows:

$\mathrm{WTP}=f($ road tax price $(\mathrm{bid})$, income, age, marital status, race, employment status, education $)$

$$
\mathrm{Z}=\beta_{0}+\beta_{1} X_{1}+\beta_{2} X_{1}+\beta_{3} X_{3}+\beta_{4} X_{4}+\beta_{5} X_{5}+\beta_{6} X_{6}+\beta_{7} X_{7}+\mathrm{v}_{i}
$$

Where:

$$
\begin{aligned}
\mathrm{Z} & =\log \text { (probability of yes response/ probability of no response); } \\
\beta_{0}, \ldots, \beta_{k} & =\text { estimated coefficient parameters; } \\
X_{1} & =\text { bid (the RM amount posed to the respondents in the WTP question); } \\
X_{1}, \ldots ., X_{k} & =\text { independent variables hypothesized to influence WTP; } \\
\mathrm{v}_{i} & =\text { random disturbance term; and }
\end{aligned}
$$


$\beta_{0}, \beta_{1}, \beta_{2}, \beta_{3}, \beta_{4}, \beta_{5}, \beta_{6}$ and $\beta_{7}$ show the changes in the dependent variables when there is a unit change in each independent variable.

This study hopes to measure the total value for this situation. Thus, it utilized CVM as the authors are more concerned with measuring the adjustment of total values. Fundamentally, there are three parts in CVM as found in Mitchell and Carson (1989). Firstly, there was a presentation and elaboration of the hypothetical market and the scenario based on the good or service being offered. Secondly, respondents answered questions related to their willingness to pay (WTP) in the given scenario. Lastly, questions on WTP were assessed in relation to the socioeconomic and demographic characteristics of the respondents. The initial phase in CVM was to set up the hypothetical market. This phase appeared to the respondents during the survey. It is critical that the respondents must comprehend the situation of scenario carefully so that their response will provide relevant outcomes.

\section{Result and Discussion}

The demographic distribution of respondents is presented in Table 1.2. The survey was conducted among 427 respondents, of which 215 are males and 212 are females. The age of the respondents ranges from 17 years old to above 60 years old. Of the total respondents, $58.1 \%$ are married while the rest are either single $(40.3 \%)$, divorced $(0.9 \%)$ or widowed $(0.7 \%)$. In term of the respondents' races, majority of them are Malay (62.3\%) and the rest are Chinese (18.7\%), Indian (17.6\%) and others (1.4\%). The respondents also include a fair number of undergraduates $(57.4 \%)$, followed by Diploma holders $(23 \%)$, postgraduates $(15.7 \%)$ and lastly, secondary school leavers (4\%). Their income level ranges from below RM2,000 to above RM7,000. From Table 1.2, it can also be observed that a significant number of the respondents work in the private sector $(64.6 \%) ; 22.2 \%$ of them work in the government sector, while the rest are either self-employed (7.0\%), working in semi-government sectors $(4.4 \%)$ or having other working experience (1.6\%).

Table 1.2: The Socio-Demographic Findings

\begin{tabular}{clcc}
\hline No. & Demographic Variable & n & \% \\
\hline 1 & Gender & & \\
& Male & 215 & 50.4 \\
& Female & 212 & 49.6 \\
Age & & \\
& 17-29 Years old & 82 & 19.2 \\
30-39 Years old & 129 & 30.2 \\
& 40-49 Years old & 102 & 23.9 \\
& 50-59 Years old & 88 & 20.6 \\
60 and Above & 26 & 6.1 \\
Race & & \\
& Malay & 266 & 62.3 \\
& Chinese & 80 & 18.7 \\
& Indian & 75 & 17.6 \\
& Others & 6 & 1.4 \\
Income & & 8.7 \\
& RM0-RM2000 & 37 & 6.8 \\
& RM2001-RM3000 & 29 & 23.2 \\
& RM3001-RM4000 & 99 & 23.9
\end{tabular}




\begin{tabular}{|c|c|c|c|}
\hline & RM5001-RM6000 & 85 & 19.9 \\
\hline & RM6001-RM7000 & 42 & 9.8 \\
\hline & RM7001 and above & 33 & 7.7 \\
\hline \multirow[t]{5}{*}{4} & Marital & & \\
\hline & Single & 172 & 40.3 \\
\hline & Married & 248 & 58.1 \\
\hline & Divorced & 4 & .9 \\
\hline & Widowed & 3 & .7 \\
\hline \multirow[t]{5}{*}{5} & Education & & \\
\hline & Secondary School & 17 & 4.0 \\
\hline & Diploma & 98 & 23.0 \\
\hline & Undergraduate & 245 & 57.4 \\
\hline & Postgraduate & 67 & 15.7 \\
\hline \multirow[t]{6}{*}{6} & Employment & & \\
\hline & Government & 95 & 22.2 \\
\hline & Semi-Government & 19 & 4.4 \\
\hline & Private & 276 & 64.6 \\
\hline & Self-Employed & 30 & 7.0 \\
\hline & Others & 7 & 1.6 \\
\hline
\end{tabular}

The dichotomous choice CVM was used for the analysis. In the dichotomous choice CVM, the respondents were asked whether they would be willing to pay a particular price in percentage (\%) for the road tax price of current non-green vehicles. They chose the 'yes' or 'no' responses to the road tax price increase by percentage offered (bid). Bids between $3 \%$ and $9 \%$ were assigned in this survey. The distribution of respondents' willingness to pay (WTP) for each bid amount is shown in Table 1.3.

Table 1.3: Consumer's Willingness To Pay

\begin{tabular}{ccccc}
$\begin{array}{c}\text { Price } \\
(\boldsymbol{\%})\end{array}$ & Freq & No & \multicolumn{2}{c}{ Yes } \\
\hline $\mathbf{3}$ & 37 & 8.63 & 396 & 91.37 \\
\hline $\mathbf{5}$ & 117 & 27.02 & 316 & 72.98 \\
\hline $\mathbf{7}$ & 123 & 28.37 & 310 & 71.63 \\
\hline $\mathbf{9}$ & 167 & 38.56 & 266 & 61.44 \\
\hline
\end{tabular}

From the 445 questionnaires distributed and returned, 427 were found useful for the analysis. The remaining 18 questionnaires were not useful for the analysis due to the respondents' failure to answer certain questions, fractional responses and not enough information. Findings show that $322(75.40 \%)$ out of the 427 respondents are willing to pay the given bid while 111 (24.60\%) are not willing to pay. The result is consistent with the concept of willingness to pay (WTP) expectation (Le Gall-Ely, 2009); as the given bid increases, the number of respondents willing to pay decreases. Hence, there is negative relationship between WTP and conservation price.

\section{Dichotomous Model Using Stata}

A data set of vehicle users in Malaysia was used to illustrate the estimation of willingness to pay (WTP) using the dichotomous model in Stata. The data set captures willingness to pay 
(WTP) as the increasing price of road tax in percentage towards non-green vehicles, in order avoid the increasing number of vehicles on the road particularly non-green vehicles which could contribute to the increasing $\mathrm{CO}_{2}$ in the environment.

Table 1.4: Result of Simple Means

\begin{tabular}{lllll}
\hline Variables & $\begin{array}{l}\text { Coefficient } \\
(\boldsymbol{\beta})\end{array}$ & $\begin{array}{l}\text { Std. } \\
\text { Error }\end{array}$ & t-ratio & p-value \\
\hline Bid1 & $-0.4231 * * *$ & 0.0753 & -5.62 & 0.0000 \\
WTP & $7.8566^{* * * *}$ & 0.4839 & 16.24 & 0.0000 \\
\hline Summary Statistic & & & & \\
No of observations & & 427 & & \\
Log Likelihood & & -228.8089 & & \\
Pseudo $\boldsymbol{R}^{\mathbf{2}}$ & & 0.0716 & & \\
\hline Significant at $1 *, * *$ Significant at 5\%, *Significant at 10\% & & \\
\hline
\end{tabular}

Notes: $* * *$ Significant at $1 *, * *$ Significant at $5 \%, *$ Significant at $10 \%$

Based on the above results, we can observe that the bid variable is statistically significant and as the bid goes up the probability of getting positive responses reduces. It means that respondents are likely to be willing to pay when the percentage bid is lower. When no control variables are included in the estimate, the average WTP is close to 7.8\% increase from the road tax price. For instance, vehicle of 1.0cc with RM20.00 road tax price will become RM21.56. The next model includes the variables age, gender, employment, education.

Table 1.5: Result of Single-Bounded

\begin{tabular}{lllll}
\hline Variables & $\begin{array}{l}\text { Coefficient } \\
(\boldsymbol{\beta})\end{array}$ & $\begin{array}{l}\text { Std. } \\
\text { Error }\end{array}$ & t-ratio & p-value \\
\hline Bid1 & $-0.6007 * * *$ & 0.0993 & -6.05 & 0.0000 \\
Age & $0.3681^{* *}$ & 0.1884 & 1.95 & 0.051 \\
Gender & $0.5092^{*}$ & 0.2749 & 1.85 & 0.064 \\
Employ & 0.1122 & 0.1493 & 0.75 & 0.452 \\
Edu & 0.2934 & 0.2171 & 1.35 & 0.176 \\
Income & $0.6607 * * *$ & 0.1508 & 4.38 & 0.000 \\
\hline Summary Statistic & & 427 & \\
$\begin{array}{l}\text { No of observations } \\
\text { Log Likelihood }\end{array}$ & & -175.4569 & & \\
Pseudo $\boldsymbol{R}^{\mathbf{2}}$ & & 0.2881 \\
Significant at 1\%*,*Significant at 5\%, *Significant at $10 \%$ & & \\
\hline
\end{tabular}




\begin{tabular}{lcccc}
\hline Variables & $\begin{array}{c}\text { Coefficient } \\
(\boldsymbol{\beta})\end{array}$ & $\begin{array}{c}\text { Std. } \\
\text { Error }\end{array}$ & t-ratio & p-value \\
\hline WTP & $7.9176^{* * * *}$ & 0.4282 & 18.49 & 0.000 \\
\hline Summary Statistic & & & \\
No of observations & 427 & & \\
Log Likelihood & -457.9231 & & \\
Significant at $1 \% *, * *$ Significant at $5 \%, *$ Significant at $10 \%$ & &
\end{tabular}

Notes: ***Significant at $1 \% * * *$ Significant at 5\%, *Significant at $10 \%$

Based on the result, it can be observed that when all the variables are included in the model, most of them are statistically significant except for employment status and education. All variables show the positive sign which is an indication of positive relationship. Females are more likely to give positive responses; the same is true for younger people. Even though employment status and education are not significant, the result shows that respondents with higher level of education tend to attract positive relationship and the same goes to employment status. In terms of the income level among respondents also shows positive relationship which means increase of income will increase percentage of willingness to pay. The average WTP is $7.9 \%$, which is not different when all control variables are included in the model and evaluated at their mean values.

\section{Double-Bounded Model Using Stata}

An issue with the economic valuation method is that every individual gives very little information regarding his/her ability to pay. This implies that in order to acquire precise estimations of WTP, huge samples are required. Hanemann et al. (1991) recommended another option to enhance the effectiveness of this estimation. This option is known as the dichotomous inquiry with follow-up or double-bounded model. For this model, a subsequent dichotomous inquiry was asked after the first dichotomous choice question. In the event that the respondent answers yes to the first question, then he is approached about his WTP for a higher amount. When the respondent answers "no" to the first question, then a lower amount is offered. This infers the second question is endogenous as the amount approached relies upon the appropriate response to the first question which is exogenous. With this strategy, we have two responses for every person, which furnishes us with more information.

Table 1.6: Result of Simple Means

\begin{tabular}{lllll} 
Variables & $\begin{array}{l}\text { Coefficient } \\
(\boldsymbol{\beta})\end{array}$ & $\begin{array}{l}\text { Std. } \\
\text { Error }\end{array}$ & t-ratio & p-value \\
\hline Beta & $6.4484 * * *$ & 0.2179 & 29.59 & 0.0000 \\
Sigma & $3.8980 * * *$ & 0.2606 & 14.96 & 0.0000 \\
\hline Summary Statistic & & & & \\
$\begin{array}{l}\text { No of observations } \\
\text { Log Likelihood }\end{array}$ & & 427 & & \\
Significant at 1\%*,**Significant at 5\%, *Significant at 10\% & &
\end{tabular}

Notes: ***Significant at $1 \% *, * *$ Significant at $5 \%$, *Significant at $10 \%$

In view of the above outcome, we have variable that catches the response to the second question and we can evaluate the second bid amount that was offered from the econometric model. Since the doubled command specific estimates $\beta$, the WTP equation is basically $\check{z} \beta$. Along these lines or situation, there is no control variable as WTP is essentially constant and is roughly 
equivalent to $6.45 \%$. As in the past case, the following stage to estimate the same WTP varies with control variables.

Table 1.7: Result of Double-Bounded

\begin{tabular}{|c|c|c|c|c|}
\hline Variables & $\begin{array}{c}\text { Coefficient } \\
(\beta)\end{array}$ & $\begin{array}{l}\text { Std. } \\
\text { Error }\end{array}$ & t-ratio & p-value \\
\hline \multicolumn{5}{|l|}{ Beta } \\
\hline Age & $0.7179 * * *$ & 0.2352 & 3.05 & 0.002 \\
\hline Gender & $0.9428 * *$ & 0.3731 & 2.53 & 0.012 \\
\hline Employ & -0.2607 & 0.2062 & -1.26 & 0.206 \\
\hline Edu & $0.6291 *$ & 0.2919 & 2.15 & 0.031 \\
\hline Income & $0.8102 * * *$ & 0.1711 & 4.74 & 0.000 \\
\hline \multicolumn{5}{|l|}{ Summary Statistic } \\
\hline No of observations & & 427 & & \\
\hline Log Likelihood & & -457.9231 & & \\
\hline \multicolumn{5}{|c|}{ ignificant at $1 \% *, * *$ Significant at $5 \%, *$ Significant at $10 \%$} \\
\hline Variables & $\begin{array}{c}\text { Coefficient } \\
(\beta)\end{array}$ & $\begin{array}{l}\text { Std. } \\
\text { Error }\end{array}$ & t-ratio & p-value \\
\hline WTP & $6.4992 * * *$ & 0.1875 & 34.67 & 0.000 \\
\hline \multicolumn{5}{|l|}{ Summary Statistic } \\
\hline No of observations & & 427 & & \\
\hline Log Likelihood & & -457.9231 & & \\
\hline
\end{tabular}

In view of the result obtained, the WTP which was assessed utilizing the average values for the explanatory variables is equivalent to $6.49 \%$. In this situation, the vast majority of variables of concern are significant aside from employment status which is not significant and has a negative sign. It implies that evaluating WTP separately for employment status might not be extremely pertinent. This is because the results obtained did not show a huge gap between the two models. The value of WTP in double-bounded should be lowered compared to the single-bounded as well as a bid choice given in follow-up questions. The result indicates that estimators perform better in double-bounded compared to single-bounded case as the estimators in double-bounded are dependent on the second bid values.

\section{Conclusion}

The study assessed consumers' willingness to pay (WTP) of road tax price for non-green vehicles. The value of WTP obtained from the contingent valuation method (CVM) was $6.5 \%$. It means that most of the respondents who are willing to pay the maximum value of $6.49 \%$ increase from the road tax price of non-green vehicles. The use of Green vehicles can be an initiative towards better environmental condition as a result of the reduction in the levels of emission from current non-green vehicles. On the other hand, it is impossible to make it compulsory for everyone to change their current vehicles to green vehicle. Therefore, "Vehicle Road Excise Duty" should be created as well as it increases the percentage of the road tax price towards non-green vehicles on the road. By implementing this kind of taxes, government could devote more resources to reduce environmental problems. The increasing price will be measured in terms of cubic centimetres (cc) of the vehicles, which means the higher cc of the vehicles, the higher the amount to be paid; since there is a high emission rate from vehicles with higher cc (non-green vehicles). On the other hand, the exemption of green vehicles from 
the environmental taxes should be replaced with other schemes. This is because green vehicles do not really have low cc too; nonetheless, they have lower emission level compared to the nongreen vehicles. This payment program should be created to control the devastating consequences that affect human beings and the environment. This is based on the outcome of the CVM methods adopted in this study which suggest that WTP value responds positively to the bid offered towards increase in the percentage of the road tax price of non-green vehicles. People refused to contribute because they think that environmental issue is the responsibility of the authorities.

\section{References}

Barth, M., \& Boriboonsomsin, K. (2008). Real-world carbon dioxide impacts of traffic congestion. Transportation Research Record: Journal of the Transportation Research Board, (2058), 163-171.

Beliveau, M. (2010). A study on hybrid cars: Environmental effects and consumer habits (Doctoral dissertation, Worcester Polytechnic Institute).

Bonini, S., \& Oppenheim, J. (2008). Cultivating the green consumer. Stanford Social Innovation Review, 6(4), 56-61.

Brownstone, D., Bunch, D.S., \& Train, K., (2000). Joint mixed logit models of stated and revealed preferences for alternative-fuel vehicles. Transportation Research Part B 34, $315-338$.

Chapman, L. (2007). Transport and climate change: a review. Journal of transport geography, 15(5), 354-367.

Chua, S. C., \& Oh, T. H. (2010). Review on Malaysia's national energy developments: Key policies, agencies, programmes and international involvements. Renewable and Sustainable Energy Reviews, 14(9), 2916-2925.

Creusen, M. E. (2010). The importance of product aspects in choice: the influence of demographic characteristics. Journal of Consumer Marketing, 27(1), 26-34.

Goodall, C. (2007). How to live a low carbon life: the individual's guide to stopping climate change (1st Edition), United Kingdom: Earthscan.

Hanemann, W. M. (1991). The Economic Theory of WTP and WTA, In Valuing Environmental Preferences: Theory and Practice of the Contingent Valuation Method in the US, EU and Developing Countries. (eds. I. J. Bateman and K. G. Wills), Oxford University Press, Oxford. Pp. 42-96.

Heffner, R.R., Kurani, K.S., \&Turrentine, T.S. (2007): Symbolism in California's early market for hybrid electric vehicles. Transp. Res. Part D 12, 396-413.

Heffner, R.R., Kurani, S.K. \&Turrentine, S.T. (2007). Symbolism and the adoption of fuel-cells vehicles, The World Electric Vehicle Association Journal, 1, pp. 24-31.

Hensher, D.A., (1982). Functional measurements, individual preferences and discrete choice modeling: theory and application. Journal of Econometric Psychology 2, 323-335.

Heutel, G., \& Muehlegger, E. (2008). Learning, externalities and hybrid vehicle adoption. University of North Carolina at Greensboro.

Heutel, G., \& Muehlegger, E. (2015). Consumer learning and hybrid vehicle adoption. Environmental and resource economics, 62(1), 125-161.

Oliver, J. D., \& Lee, S. H. (2010). Hybrid car purchase intentions: a cross-cultural analysis. Journal of consumer marketing, 27(2), 96-103.

J.D. Power \& Associates, (2008). While many new-vehicle buyers express concern for the environment, few are willing to pay more for an environmentally friendly vehicle. http://www.jdpower.com/corporate/news/releases/pressre lease.aspx? $\mathrm{ID}=2008029 \mathrm{~S}$ (Accessed: 20/12/2016). 
Jomo, K. S. (1994). The Proton Saga. Japan and Malaysian Development, London: Routledge, 263-290.

Kasipillai, J., \& Chan, P. (2008). Travel demand management: lessons for Malaysia. Journal of Public Transportation, 11(3), 3.

Kazdin, A. E. (2009). Psychological science's contributions to a sustainable environment: Extending our reach to a grand challenge of society. American Psychologist, 64(5), 339.

Kishi, K., \& Satoh, K., (2005). Evaluation of willingness to buy a low-pollution car in Japan. Journal of the Eastern Asia Society for Transportation Studies 6, 3121-3134.

Le Gall-Ely, M. (2009). Definition, measurement and determinants of the consumer's willingness to pay: a critical synthesis and avenues for further research. Rechercheet Applications en Marketing (English Edition), 24(2), 91-112.

Malaysia Automotive Institute (2016) Total Vehicles Sales in Malaysia. Retrieved from: http://mai.org.my/v5test/index.php?option=com_content\&view=article\&id=4\&Itemid $=168 \&$ lang=en (Accessed: 12/8/2017).

Mitchell, R. C., \& Carson, R. T. (2013). Using surveys to value public goods: the contingent valuation method. Rff Press.

Oliver, J. D., \& Lee, S. H. (2010). Hybrid car purchase intentions: a cross-cultural analysis. Journal of consumer marketing, 27(2), 96-103.

Potoglou, D., \& Kanaroglou, P.S. (2007). Household demand and willingness to pay for clean vehicles. Transportation Research Part D 12, 264-274.

Ramjerdi, F., \& Rand, L. (2000). Demand for clean fuel car in Norway. In URBAN TRANSPORT SYSTEMS. PROCEEDINGS FROM THE 2ND KFB RESEARCH CONFERENCE IN LUND, SWEDEN, 7-8 JUNE 1999 (BULLETIN 187) (No. 187: 01).

Road Transport Department Malaysia (2016) Price List of Road Tax in Malaysia. Retrieved from: http://www.jpj.gov.my/ (Accessed: 12/9/2017).

Wef, W. E. (2015). Travel and Tourism Competitiveness Report. In Geneva: World Economic Forum. 